\title{
Splenic Manifestation of Chronic Lymphocytic Leukemia
}

National Cancer Institute

\section{Source}

National Cancer Institute. Splenic Manifestation of Chronic Lymphocytic Leukemia. NCI Thesaurus. Code C7300.

Infiltration of the spleen by chronic lymphocytic leukemia. It primarily involves the white pulp. 